\title{
Assembly of Layered Monetite-Chitosan Nanocomposite and Its Transition to Organized Hydroxyapatite
}

\author{
Qichao Ruan ${ }^{\dagger}$, David Liberman ${ }^{\dagger}$, Yuzheng Zhang ${ }^{\ddagger}$, Dongni Ren ${ }^{\dagger}$, Yunpeng Zhang ${ }^{\ddagger}$, Steven \\ Nutt $^{\ddagger}$, and Janet Moradian-Oldak ${ }^{*}, \dagger$ \\ †Center for Craniofacial Molecular Biology, Herman Ostrow School of Dentistry, University of \\ Southern California, 2250 Alcazar Street, Los Angeles, California 90033, United States \\ ¥Mork Family Department of Chemical Engineering and Materials Science, University of Southern \\ California, 3651 Watt Way, Los Angeles, California 90089, United States
}

\begin{abstract}
Bioinspired synthesis of hierarchically structured calcium phosphate $(\mathrm{CaP})$ material is a highly promising strategy for developing improved bone substitute materials. However, synthesis of $\mathrm{CaP}$ materials with outstanding mechanical properties still remains an ongoing challenge. Inspired by the formation of lamellar structure in nacre, we designed an organic matrix composed of chitosan and cis-butenediolic acid (maleic acid, MAc) that could assemble into a layered complex and further guide the mineralization of monetite crystals, resulting in the formation of organized and parallel arrays of monetite platelets with a brick-and-mortar structure. Using the layered monetitechitosan composite as a precursor, we were able to synthesize hydroxyapatite (HAp) with multiscale hierarchically ordered structure via a topotactic phase transformation process. On the nanoscale, needlelike HAp crystallites assembled into organized bundles that aligned to form highly oriented plates on the microscale. On the large-scale level, these plates with different crystal orientations were stacked together to form a layered structure. The organized structures and composite feature yielded $\mathrm{CaP}$ materials with improved mechanical properties close to those of bone. Our study introduces a biomimetic approach that may be practical for the design of advanced, mechanically robust materials for biomedical applications.
\end{abstract}

\section{Graphical abstract}

\footnotetext{
*Corresponding Author: joldak@usc.edu. Tel.: +1 323442 1759. Fax: +1 3234422981.

Supporting Information

The Supporting Information is available free of charge on the ACS Publications website at DOI: 10.1021/acsbiomaterials.6b00164. Figure S1, schematic representation of the hierarchical assembly process of organized chitosan-MAc matrix based on the data in Figure 2-4; Figure S2, EDS and FTIR spectra of the layered monetite-chitosan-MAc composite; Figure S3, SEM images of the monetite crystals obtained without organic matrix, with chitosan alone, and with maleic acid alone; Figure S4, schematic representation of the formation of layered monetite-chitosan-MAc composite; Figure S5, XRD and EDS spectra of the organized HAp-chitosan-MAc composite; Figure S6, crystal structures of monetite and hydroxyapatite; Figure S7, representative photographic image of a CaP tablet prepared from layered monetite-chitosan-MAc composite (PDF)

Notes

The authors declare no competing financial interest.
} 


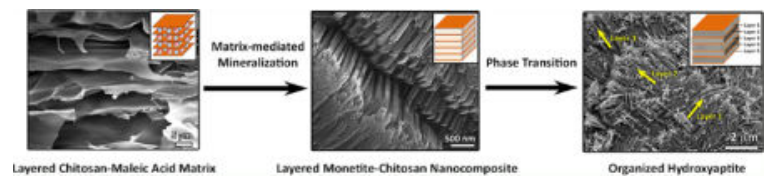

\section{Keywords}

bioinspired matrix; monetite; hierarchical structure; hydroxyapatite; chitosan; maleic acid

\section{INTRODUCTION}

Calcium phosphates $(\mathrm{CaP})$ are important biomaterials in the fields of tissue engineering and drug delivery, because of their low toxicity, excellent biocompatibility, and osteoconductivity. For example, nanostructured $\mathrm{CaP}$ materials have been used in biomedical products such as scaffolds for bone regrowth, ${ }^{1}$ bioactive coatings and composites, ${ }^{2}$ carriers for drug delivery, ${ }^{3}$ and bioactive fillers for the occlusion of exposed dentin tubules. ${ }^{4}$ However, the application of conventional $\mathrm{CaP}$ materials as hard tissue substitutes has been largely restricted by their brittleness and low strength. Progress to reinforce their mechanical properties through incorporation of high-strength materials in the $\mathrm{CaP}$ matrix has been incremental. 5,6 Therefore, there is a need for an effective alternative strategy to boost the mechanical properties of synthetic $\mathrm{CaP}$ materials in a way to broaden their application in the areas of repair of multiple fractures of long bones, or vertebral body substitution. ${ }^{7}$

The hierarchical structure of biological composites has inspired scientists to develop highperformance materials with superior properties and functionalities. ${ }^{8-12}$ Natural structural materials such as nacre, bone, and tooth exhibit excellent mechanical performance associated with their composition and unique hierarchical structures. For instance, the lamellar architectures in nacre and bone are well-known structures that provide these biocomposites with mechanical properties that far exceed those of their constituent materials. ${ }^{13}$ Another prime example, tooth enamel, consists of densely packed arrays of elongated apatite crystals organized into an intricate interwoven structure. ${ }^{14}$ Because of its unique architecture and dense mineral components, mature enamel possesses remarkably high elastic modulus and hardness, which are rarely achieved in artificial CaP materials. ${ }^{15,16}$ Thus, mimicking the structural features of such natural composites is a promising route to developing new structural materials with superior mechanical performance. ${ }^{13,16}$

Over the past decade, efforts to synthesize $\mathrm{CaP}$ materials with bioinspired structures have relied on methods such as freeze casting, ${ }^{17}$ vacuum-assisted filtration, ${ }^{18}$ and biomimetic mineralization. ${ }^{19,20}$ In one such study, a bioinspired hydroxyapatite/poly(methyl methacrylate) composite with a nacre-mimetic lamellar structure was prepared by a bidirectional freezing method, ${ }^{17}$ and in another, Li et al. used a vacuum-assisted-filtration method to combine $\mathrm{CaP}$ plates with amyloid fibrils to generate a hybrid nanocomposite with bone-mimetic features. ${ }^{18}$ Bioinspired $\mathrm{CaP}$ materials with bone-mimetic or enamel-like structures have also been synthesized through matrix-regulating mineralization of apatite nanocrystals with the assistance of peptides, ${ }^{21,22}$ proteins, ${ }^{23-25}$ protein-inspired polymers, ${ }^{26,27}$ block copolymers, ${ }^{28,29}$ self-assembled liquid crystals,,${ }^{19,20}$ and other organic 
additives. ${ }^{30,31}$ These promising studies illustrate steps toward the formation of intricate structures at limited scale, although synthesis of bioinspired $\mathrm{CaP}$ materials with the architectural features over multiple length scales remains a great challenge. Another promising route to achieve hierarchical structures in $\mathrm{CaP}$ materials involves the use of a precursor crystal as a template. For example, based on the structural resemblance between monetite (dicalcium phosphate anhydrous, DCPA, $\mathrm{CaHPO}_{4}$ ) and hydroxyapatite (HAp, $\left.\mathrm{Ca}_{5}\left(\mathrm{PO}_{4}\right)_{3} \mathrm{OH}\right)$ crystals, monetite was shown to be an effective precursor in the preparation of various nanostructured hydroxyapatite crystals. ${ }^{32-34}$ Using macrosized crystals as a template, Liu et al. synthesized ordered HAp structures via a phase transformation from monetite. ${ }^{35}$ This result demonstrated the feasibility of mimicking hierarchical designs of natural structures via a phase transformation from precursor crystals. However, the timeconsuming preparation of the macro-sized monetite precursor (3 to 6 months) challenged its suitability for broader applications. Generating multilevel hierarchy is still a huge challenge in the fabrication of HAp from the direct transformation of a single monetite crystal.

In the present study, we report a biomimetic strategy, inspired by the formation of brick-andmortar structure in nacre, to generate a layered monetite-based composite that can further transform into a HAp-chitosan composite with a multilevel hierarchical structure. In nacre, the orderly layered structure forms under the mediation of an organic matrix composed of $\beta$ chitin, silklike proteins, and acidic glycoproteins rich in aspartic acid (Asp). ${ }^{36-38}$ Among these components, the oriented fibrils of $\beta$-chitin play an important role in regulating the crystal orientation, and the Asp-rich proteins are believed to interact both with the $\beta$-chitin substrate and the growing crystals. ${ }^{36}$ Considering the critical functions of $\beta$-chitin and acidic proteins, our strategy starts with the rational design of an organic medium composed of chitosan and cis-butenediolic acid (maleic acid, MAc) to mimic the function of nacreous matrix and to generate an ordered layered structure. Chitosan is a deacetylated derivative of chitin usually used to study the crystallization process instead of chitin, owing to its soluble properties in acidic media. Experiments have shown that chitosan scaffolds are capable of promoting the formation of randomly spherelike, rodlike, or platelike CaP crystals, ${ }^{39-41}$ yet no observable higher-order structure has been reported in these materials, perhaps because of the absence of orderly assembly of the pristine chitosan molecules. ${ }^{42}$ To overcome this problem, here we introduced a dicarboxylic MAc molecule that could serve as a crosslinking agent and lead to the intermolecular assembly of an organized matrix (Figure 1, step (i)). In addition to the cross-linking capability, the carboxyl functional groups of MAc could also afford the matrix with interactive sites to nucleate the monetite crystals and mediate the formation of a layered structure (Figure 1, step (ii)). Using this layered monetite precursor, we were able to synthesize a hierarchical composite with orderly bundlelike structures on the nanoscale as well as layered organization on the microscale through a controlled phase transformation process (Figure 1, step (iii)). These hierarchical structures are expected to provide $\mathrm{CaP}$ materials with improved mechanical properties and potential for future hard tissue engineering applications. 


\section{MATERIALS AND METHODS}

\section{Analyses of Chitosan-MAc Matrix}

To investigate the assembly of the layered matrix, we prepared the chitosan-MAc solution by dissolving $0.25 \mathrm{~g}$ of chitosan (medium molecular weight, 75-85\% deacetylated, SigmaAldrich) and $0.1 \mathrm{~g}$ of maleic acid (MAc, Sigma-Aldrich) in $25 \mathrm{~mL}$ of deionized water containing $0.72 \mathrm{~mL}$ of acetic acid under magnetic stirring, and the $\mathrm{pH}$ value was adjusted to 3.5 with $1 \mathrm{M} \mathrm{NaOH}$. The solid phase of chitosan-MAc matrix was obtained by lyophilization for scanning electron microscopy (SEM), X-ray diffraction (XRD), and Fourier transform infrared spectroscopy (FTIR) studies. For circular dichroism (CD), atomic force microscopy (AFM) and transmission electron microscopy (TEM) studies, $0.1 \mathrm{~mL}$ of chitosan-MAc solution was diluted with $0.9 \mathrm{~mL}$ deionized water. The TEM sample was prepared by depositing a droplet of the diluted chitosan-MAc solution onto a TEM grid and then staining it with a droplet of a $0.1 \mathrm{wt} \%$ phosphotungstic acid aqueous solution.

\section{Preparation of Layered Monetite-Chitosan-MAc Composite}

Six grams of urea, $0.25 \mathrm{~g}$ of chitosan (medium molecular weight, $75-85 \%$ deacetylated, Sigma-Aldrich) and $0.1 \mathrm{~g}$ of maleic acid (MAc, Sigma-Aldrich) were dissolved in $25 \mathrm{~mL}$ of deionized water containing $0.72 \mathrm{~mL}$ of acetic acid under magnetic stirring. Then, $0.3 \mathrm{~g}$ of $\mathrm{NaH}_{2} \mathrm{PO}_{4}$ and $0.614 \mathrm{~g}$ of $\mathrm{CaCl}_{2} \cdot 2 \mathrm{H}_{2} \mathrm{O}$ were dissolved into the solution under vigorous stirring for $2 \mathrm{~h}$, and the $\mathrm{pH}$ value was adjusted to 3.5 with $1 \mathrm{M} \mathrm{NaOH}$. Next, the reaction solution was heated in a water bath at $70{ }^{\circ} \mathrm{C}$ for $4.5 \mathrm{~h}$, then allowed to cool down to room temperature naturally. Following the reaction, the obtained suspension was centrifuged and washed with distilled water and anhydrous ethanol several times. Finally, the sample was frozen on dry ice and lyophilized for $16 \mathrm{~h}$.

\section{Preparation of Organized HAp-chitosan-MAc Composite via Phase Transition}

Layered monetite-chitosan-MAc composite $(0.15 \mathrm{~g})$ was dispersed in $15 \mathrm{~mL}$ of $\mathrm{NaOH}$ solution $(0.1 \mathrm{M}, \mathrm{pH} 13)$ and kept in a water bath under vigorous stirring at $70{ }^{\circ} \mathrm{C}$ for $5 \mathrm{~min}$. The suspension was then immediately centrifuged and washed with distilled water and anhydrous ethanol several times. Finally, the sample was frozen on dry ice and lyophilized overnight.

\section{Preparation of Calcium Phosphate Tablets}

The CaP tablets were prepared by pressing the layered monetite-chitosan-MAc or organized HAp-chitosan-MAc composite in a stainless steel mold under a pressure of $10 \mathrm{MPa}$ at $130{ }^{\circ} \mathrm{C}$ for $48 \mathrm{~h}$.

\section{Characterization}

SEM imaging was performed in a JSM-7001F field emission scanning electron microscope (JEOL, Peabody, MA) operating at an accelerating voltage of 5-15 kV. XRD patterns were recorded by a Rigaku diffractometer with $\mathrm{Cu} \mathrm{K} a$ radiation $(\lambda=1.542 \AA)$ operating at $70 \mathrm{kV}$ and $50 \mathrm{~mA}$ with a step size of $0.02^{\circ}$, at a scanning rate of $0.1^{\circ} / \mathrm{sec}$ in the $2 \theta$ range $10-60^{\circ}$. TEM images were obtained on a JEOL JEM-2100 microscope using an accelerating voltage 
of $200 \mathrm{kV}$. CD spectropolarimetry was performed using a J-815 spectropolarimeter (JASCO, Easton, MD). The spectra were recorded between 190 and $260 \mathrm{~nm}$ with a step size of $0.5 \mathrm{~nm}$ and a scan rate of $50 \mathrm{~nm} / \mathrm{min}$. AFM images were obtained by using a NanoScopeIIIa scanning probe microscope system (Digital Instruments, Tonawanda, NY) with a tapping mode etched silicon probe (model OTESPA-10) in air at scanning rates of $0.5-1.0 \mathrm{~Hz}$ for different resolutions. FTIR spectra were acquired from a Nicolet 4700 Spectrometer with a Gladi-ATR diamond crystal accessory. Thermogravimetry (TGA) analysis was performed on a Q5000 IR (TA Instruments, New Castle, DE) with a heating rate of $50{ }^{\circ} \mathrm{C} / \mathrm{min}$, under an air flow of $20 \mathrm{~mL} / \mathrm{min}$ from 30 to $900{ }^{\circ} \mathrm{C}$. The hardness and elastic modulus were measured at 25 test points in each sample $(n=3)$ using a nanoindenter (Agilent-MTS XP) with a Berkovich tip.

\section{Statistical Analysis}

The experiments were conducted in triplicate and the data were expressed as mean \pm standard deviations. Student's $t$ test was applied to identify differences in the hardness and elastic modulus between layered monetite-based composite and hierarchical HAp-based composite. The differences were considered statistically significant at $p<0.05$ and highly significant at $p<0.001$. All the statistical analyses were carried out using Origin 8.0 (Origin lab, Northampton, MA) and Microsoft Office Excel 2007.

\section{RESULTS AND DISCUSSION}

\section{Assembly of Organized Chitosan-MAc Matrix}

Unlike the chitin in nacre matrix, chitosan alone does not form an organized structure because it lacks the acetylamide groups that contribute to hydrogen bonding during the selfassembly of chitin. ${ }^{42}$ In our study, only irregularly spherical-like morphology can be observed when examining pure chitosan (Figure 2a, b). Inspired by the critical role of intermolecular interaction in chitin assembly, we included maleic acid (MAc) into the chitosan matrix to provide an interactive cross-linker and facilitate the orderly assembly of the organic matrix.

Figures 2c, d show the sheetlike morphology of the organic matrix composed of chitosan and MAc. These chitosan-MAc sheets are stacked in parallel layered structures similar to the organized structures seen in nacreous matrix. ${ }^{43}$ In addition, the XRD pattern of chitosanMAc matrix displays a diffraction peak at a spacing of $0.37 \mathrm{~nm}$ (Figure 2e), representing short-range order in the chitosan-MAc molecular complex (Figure 2f). These observations demonstrate the ordered coassembly of chitosan-MAc matrix due to the specific interaction between chitosan and MAc, which was further confirmed by FTIR. Compared with the FTIR spectra of pure chitosan or MAc, the COO- stretch vibration band shifted from 1703 to $1710 \mathrm{~cm}^{-1}$ in the spectra of chitosan-MAc mixture (Figure 3a), and the $\mathrm{N}-\mathrm{H}$ bending vibration band shifted from 1581 to $1512 \mathrm{~cm}^{-1}$ (Figure 3b).

These shifts indicate a strong interaction between the charged carboxyl and amine groups. ${ }^{42,44,45}$ Indeed, under our experimental conditions $(3.5<\mathrm{pH}<4.5)$, the amine groups of chitosan $\left(\mathrm{p} K_{\mathrm{a}}=6.5\right)$ are protonated to form positively charged chains. ${ }^{46}$ Simultaneously, 
the two carboxyl ends of MAc $\left(\mathrm{p} K_{\mathrm{a}}=1.92\right)$ are fully ionized. ${ }^{47}$ As a result, the chitosan chains can be cross-linked by MAc molecules through hydrogen bonding and electrostatic interactions between the positively charged amine groups and the negatively charged carboxyl groups (Figure 2f). The specific chitosan-MAc interaction is expected to cause a conformational change in the chitosan molecule, which is confirmed by the circular dichroism (CD) spectropolarimetry. As shown in Figure 3c, the CD spectrum of pure chitosan in aqueous solution $(\mathrm{pH} 3.5)$ has a broad negative $\mathrm{CD}$ band located at about 210 $\mathrm{nm}$, corresponding to the $\mathrm{n} \rightarrow \pi^{*}$ electronic transition of the $-\mathrm{NH}-\mathrm{CO}$ - chromophore of GlcNAc (N-acetyl-D-glucosamine) units. ${ }^{48}$ After adding MAc to the chitosan solution, the negative dichroic signal of chitosan is absent (Figure 3c), indicating a distinct change in the chromophore environments of the GlcNAc units due to the interaction between chitosan and MAc. ${ }^{49}$ This conformational change may give rise to an anisotropic ligand distribution in the chitosan-MAc complex that could further assist in the assembly of an organized matrix. ${ }^{50,51}$

The assembly states of pure chitosan and chitosan-MAc matrix were revealed by tapping mode atomic force microscopy (AFM) and transmission electron microscopy (TEM) under the conditions described in Figure 3. Without MAc, the chitosan chains tend to aggregate into randomly distributed nanoparticles with a size of $\sim 30 \mathrm{~nm}$ due to hydrophobic or solvophobic interactions (Figure $4 \mathrm{a}, \mathrm{c}$ ), as proposed elsewhere. ${ }^{52-55}$ In contrast, following addition of MAc we could observe linear chains of $\sim 50 \mathrm{~nm}$ nanoclusters in the chitosanMAc matrix (arrows in Figure 4b, d). We speculate that this spontaneous linear assembly depends on an equilibrium between various attractive and repulsive interactions, such as hydrophobic interaction, van der Waal's attraction, hydrogen bonding and electrostatic repulsion. ${ }^{56,57}$ The attractive forces favor more contact between nanoparticles and drive the formation of compact aggregates, although electrostatic repulsion acts as a key driving force to form anisotropic self-assemblies of 1D chains. ${ }^{58}$ The insertion of ionized MAc molecules into a chitosan system may dramatically disrupt the hydrophobic force within a close distance. ${ }^{58}$ As a result, the repulsion between neighboring chitosan-MAc nanoparticles tends to force these molecules into an ordered assembly to evenly distribute their charges. This process eventually leads to the formation of chitosan-MAc sheets that further stack into a layered structure. Based on the results discussed here (Figures 2-4), the self-assembly process of layered chitosan-MAc matrix is schematically presented in Figure S1. Using this chitosan-MAc matrix, we were able to further construct an orderly, layered monetite composite.

\section{Assembly of Layered Monetite-Chitosan-MAc Composite}

To prepare a calcium phosphate composite with an orderly layered structure, we adopted a wet-chemical precipitation method in the presence of a chitosan-MAc mixture. The resulting calcium phosphate products exhibited a brick-and-mortar structure (Figure 5a-d), in which calcium phosphate platelets with a thickness of $\sim 100 \mathrm{~nm}$ were bound together by the organic binder (arrows in Figure 5c). High-resolution transmission electron microscopy (HRTEM) and corresponding fast Fourier transform (FFT) images provide further insight into the structural details of the calcium phosphate platelets (Figure 5e). The interplanar distances measured in segments of HRTEM micrograph were 0.250 and $0.289 \mathrm{~nm}$, corresponding to the $(0 \overline{2} 2)$ and (021) planes of monetite crystals (JCPDS Card: 71-1759), respectively. The 
corresponding FFT pattern further confirms that the calcium phosphate platelet has a monetite polymorph (inset in Figure 5e) imaged along the [200] direction, indicating that the facet planes of the monetite platelets are (200).

This crystallographic characterization and composition of the layered composite were further confirmed by XRD and energy dispersive X-ray spectroscopy (EDS) (Figure $5 \mathrm{f}$ and Figure S2a). The resulting diffractogram shows that the products are mainly composed of monetite crystals (JCPDS Card: 71-1759). A strong 200 diffraction peak indicates a preferred (200) orientation of the monetite platelets in accordance with the above HRTEM analysis. In addition, a broad diffraction peak around $2 \theta=20^{\circ}$ may be ascribed to the presence of organic matrix in the layered composite. EDS reveals the presence of calcium, phosphorus, carbon, and oxygen in the layered composite. The measured $\mathrm{Ca} / \mathrm{P}$ molar ratio is 1.0, consistent with the stoichiometric ratio for monetite. The composite nature of the material is also revealed by FTIR spectroscopy and thermogravimetric analysis (TGA). For example, the typical bands of monetite, as well as the characteristic peaks for chitosan and MAc, including $\delta(\mathrm{N}-\mathrm{H})$ at $1645 \mathrm{~cm}^{-1}$ for chitosan ${ }^{44}$ and $v(\mathrm{COO}-)$ at $1555 \mathrm{~cm}^{-1}$ for MAc, ${ }^{59}$ are found in the FTIR spectrum, indicating that the precipitated monetite crystal platelets are covered with chitosan and MAc (Figure S2b). The TG curve in Figure 5g shows that the total weight loss of monetite-chitosan composite is $17.2 \%$ in the range of 100 $900{ }^{\circ} \mathrm{C}$, whereas pure monetite should give a weight loss of $6.6 \%$ when it is decomposed completely $\left(2 \mathrm{CaHPO}_{4} \stackrel{\Delta}{\rightarrow} \mathrm{Ca}_{2} \mathrm{P}_{2} \mathrm{O}_{7}+\mathrm{H}_{2} \mathrm{O}\right) .{ }^{60}$ Aside from the weight loss caused by the decomposition of monetite, the additional weight loss of $\sim 10.6 \%$ corresponds to loss of water and the organic component. The structural and compositional analyses indicate that the products synthesized in the chitosan-MAc matrix contain monetite with an organized, layered arrangement.

To investigate the assembly process of the layered monetite-chitosan-MAc composite, the $\mathrm{pH}$ of the reaction system and the product morphology were monitored at different reaction times (Figure 6). When the solution contained no $\mathrm{Ca}^{2+}$, the $\mathrm{pH}$ increased with prolonged reaction time due to the hydrolysis of urea (dotted line in Figure 6a). In contrast, a reduction in $\mathrm{pH}$ was observed in the reaction solution when the reaction time increased to $1 \mathrm{~h}$ (solid line in Figure 6a). Moreover, the addition of $\mathrm{Ca}^{2+}$ in the reaction solution resulted in lower $\mathrm{pH}$ values because of the nucleation of monetite in the system. To diminish the effect of urea hydrolysis on the $\mathrm{pH}$ change and better understand the crystallization process, the $\mathrm{pH}$ difference $(\Delta \mathrm{pH})$ between the solutions with and without $\mathrm{Ca}^{2+}$ was calculated at different reaction times. As shown in Figure 6b, the $\Delta \mathrm{pH}$ rose from 0 to 0.5 within the first hour of reaction and dropped to $\sim 0.3$ when reaction time reached $2 \mathrm{~h}$. After that, only slight changes were seen in the $\Delta \mathrm{pH}$. On the basis of these observations, the possible reaction process in the chitosan-MAc matrix can be inferred as follows (eqs 1-3).

$$
\mathrm{CO}\left(\mathrm{NH}_{3}\right)_{2}+2 \mathrm{H}_{2} \mathrm{O} \stackrel{\Delta}{\rightarrow} 2 \mathrm{NH}_{4}++2 \mathrm{OH}^{-}+\mathrm{CO}_{2}
$$




$$
\begin{gathered}
\mathrm{H}_{2} \mathrm{PO}_{4}{ }^{-}+\mathrm{OH}^{-} \rightarrow \mathrm{HPO}_{4}{ }^{2-}+\mathrm{H}_{2} \mathrm{O} \\
\mathrm{Ca}^{2+}+\mathrm{HPO}_{4}{ }^{2-} \rightarrow \mathrm{CaHPO}_{4}
\end{gathered}
$$

$\mathrm{H}_{2} \mathrm{PO}_{4}{ }^{-}$is dominant in the initial reaction solution with a $\mathrm{pH}$ of 3.5. As reaction time increases, the $\mathrm{pH}$ gradually increases due to the hydrolysis of urea (eq 1), leading to a conversion of $\mathrm{H}_{2} \mathrm{PO}_{4}{ }^{-}$to $\mathrm{H}_{2} \mathrm{PO}_{4}^{-}$(eq 2). ${ }^{61}$ When the concentration product of $\mathrm{Ca}^{2+}$ and $\mathrm{H}_{2} \mathrm{PO}_{4}{ }^{-}$is larger than the Ksp of monetite, the monetite starts crystallizing in the solution (eq 3). Meanwhile, the nucleation of crystals leads to a decrease in the $\mathrm{pH}$ of the reaction solution because of the consumption of $\mathrm{Ca}^{2+}$ and $\mathrm{OH}^{-}$(eqs 2 and 3). When the reaction time is increased to $1 \mathrm{~h}$, white precipitation of monetite is formed in the solution. The products obtained at this time consist of monetite platelets assembled in an orderly layered structure (Figure 6c). After $2 \mathrm{~h}$, there are no significant changes in $\Delta \mathrm{pH}$, indicating that the main reaction in the solution is the assembly of monetite crystals. At this stage, the initially formed crystals (Figure 6c) further stack and aggregate together (Figure 6d) and eventually form $\sim 30 \mu \mathrm{m}$ spheres, as shown in Figure 5a.

We can further consider the role of the chitosan-MAc mixture in this assembly mechanism. We did not observe any layered structure at any point during the reaction process in the absence of either chitosan or MAc. In a comparative experiment without chitosan and MAc, the monetite produced from precipitation formed plate-shaped structures with a width of 5$10 \mu \mathrm{m}$ (Figure S3a). Only platy monetite crystals were formed in the absence of MAc (Figure S3b), and only porous HAp was produced in the absence of chitosan (Figure S3c). Other evidence for the critical role of the chitosan-MAc matrix is provided in a series of experiments in which we examined the thickness of monetite crystals as a function of chitosan and MAc concentration. Remarkably, changes in the thickness of monetite crystals were observed upon altering the concentration of chitosan-MAc matrix in a dose dependent manner. As shown in Figures 7 and $5 \mathrm{~b}$, the thickness of monetite crystals decreased from $\sim 200 \mathrm{~nm}$ to $\sim 100 \mathrm{~nm}$ and $\sim 50 \mathrm{~nm}$ when the concentration of chitosan increased from $0.5 \%$ $(\mathrm{m} / \mathrm{v})$ to $1 \%(\mathrm{~m} / \mathrm{v})$ and $3 \%(\mathrm{~m} / \mathrm{v})$. (Note: the mass ratio of chitosan to maleic acid was kept steady at 2.5.) These observations suggest that the chitosan-MAc mixture is crucial to the construction of orderly layered monetite composite.

It is noteworthy that the $\mathrm{pH}$ values $(3.5<\mathrm{pH}<4.5)$ of the reaction solution are in between the $\mathrm{p} K_{\mathrm{a}}$ values of maleic acid (1.92) and chitosan (6.5) throughout the reaction process. As a result, the protonated amine groups and ionized carboxyl groups remain active and interact with each other, leading to a persistent assembly and function of the chitosan-MAc matrix during the formation of layered monetite composite. Similar to the formation of nacre, ${ }^{37,38}$ the chitosan-MAc layers not only function as a structural framework, but also provide a charged carboxylate surface that plays an important role in inducing nucleation and interacting with forming crystals. The negatively charged carboxyl groups of the chitosanMAc complex are preferentially adsorbed on the calcium-rich (100) surface of crystals to 
stabilize and confine the formation of monetite platelets. The interaction between the organic complex and the calcium ions can be verified by the appearance of a characteristic FTIR vibration of COO-Ca at $1466 \mathrm{~cm}^{-1}$ (Figure 8). ${ }^{32}$ The proposed formation process of layered monetite-chitosan-MAc composite under the mediation of chitosan-MAc matrix is summarized as follows (Figure S4). First, the negatively charged carboxyl groups of chitosan-MAc matrix act as active sites to interact with calcium and phosphate ions, inducing the heterogeneous nucleation of monetite. Then, guided by the chitosan-MAc matrix template, the monetite platelets are formed in between the layers of the chitosanMAc scaffold, and finally grow in an organized manner into an orderly layered structure.

\section{Synthesis of Organized HAp-Chitosan-MAc Composite via Phase Transition}

Using the layered monetite-chitosan-MAc composite, we were able to fabricate an organized HAp-chitosan-MAc composite via a phase transformation in an alkali solution at $70{ }^{\circ} \mathrm{C}$. XRD and EDS results confirmed that hydroxyapatite (JSPDS Card: 09-0432) was obtained after immersing the monetite-chitosan composite in a $0.1 \mathrm{M} \mathrm{NaOH}$ (pH 13) solution for 5 min (Figure S5). This process produced a multilevel ordered structure, as shown in Figure $9 \mathrm{a}-\mathrm{c}$. On the nanoscale, needlelike HAp crystallites with a diameter of $\sim 25 \mathrm{~nm}$ assembled into organized bundles (inset in Figure $9 \mathrm{~b}$ ). On the microscale, these HAp bundles aligned to form highly oriented plates about $2 \mu \mathrm{m}$ in width and $4 \mu \mathrm{m}$ in length (Figure $9 \mathrm{~b}$ ). Most interestingly, on the larger-scale level, these HAp plates with different crystal orientations stacked to form a layered structure (arrows in Figure 9c). A typical layer consisted of a HAp plate with an estimated thickness of $\sim 100 \mathrm{~nm}$, which was inherited from the monetite precursor. Clearly, the layered arrangement of the monetite precursor was preserved to some extent during the phase transformation.

During the phase transformation from monetite to HAp, the ordered nanostructure can only be obtained through a topotactic solid-solid transition under highly alkaline conditions $\left(10 \mathrm{CaHPO}_{4}+6 \mathrm{OH}^{-} \rightarrow \mathrm{Ca}_{10}\left(\mathrm{PO}_{4}\right)_{6}(\mathrm{OH})_{2}+4 \mathrm{PO}_{4}^{3-}+10 \mathrm{H}_{2} \mathrm{O}\right) \cdot{ }^{35}$ Specifically, the highly alkaline conditions generate a strong driving force that compels the ions to move and rearrange inside the crystal, resulting in a spatially periodic nucleation of HAp seeds and formation of well-arranged HAp nanoneedles on the monetite surface. However, the structural stress induced by dehydration and the movement of ions during the transition from monetite to HAp can cause changes to the crystal morphology and collapse of the layered structures. ${ }^{34,62}$ Thus, a major challenge associated with synthesis of hierarchical HAp in the present study was to preserve the layered arrangement on a larger-scale level during the phase transformation from monetite composite to HAp. One way to overcome this problem is to use an organic matrix that can protect the organized layered structures. For example, by using different biomacromolecules and surfactants, the crystal morphology can be maintained during the phase transformation from OCP to HAP because of the interaction between organic molecules and crystals. ${ }^{61}$ In a similar way, the chitosan-MAc matrix was expected to preserve the hierarchical architecture of crystals during the monetite-HAp transition by interacting with the crystal surface as discussed above.

Given all these considerations, we ascribe the formation of our hierarchical HAp to a topotactic solid-solid transformation under the mediation of the chitosan-MAc matrix. The 
intraparticle topotactic transition was revealed by HRTEM and FFT analysis. Figure 9d depicts a HRTEM image of a single crystal of hierarchical HAp-chitosan composite obtained from the transformation of a monetite crystal, which clearly exhibits the lattice fringes of the (002) plane of the HAp $(d=0.344 \mathrm{~nm})$, as well as the (020) plane of the monetite $(d=0.333 \mathrm{~nm})$. Furthermore, we can observe an amorphous region located at the monetite-HAp boundary (Figure 9d), probably indicating ion rearrangement inside the crystal. ${ }^{62}$ Additionally, the corresponding FFT image shows two different patterns containing both HAp and monetite spots (inset in Figure 9d). Note that the FFT spots of HAp and monetite are projected along the [010] and [100] axes, respectively, and the spots indexed as monetite (020) and HAp (002) nearly overlap, indicating that the (002) planes of HAp are nearly parallel to the (020) planes of the monetite crystals. These results suggest that the HAp crystals form on the (100) face of the $\mathrm{CaHPO}_{4}$ single crystals and orient along the $b$-axis of $\mathrm{CaHPO}_{4}$ because of the similarity of the $\mathrm{CaHPO}_{4}$ and $\mathrm{HAp}$ crystal structures (Figure S6). As a result, the (010) plane of $\mathrm{CaHPO}_{4}$ may transform into the (001) face of HAp, as indicated by HRTEM and FFT analysis (Figure 9d), leading to the eventual formation of HAp with bundle-like structure on the nanoscale. In addition, the chitosanMAc matrix is stable on the crystal surface because of the low solubility of chitosan under alkaline conditions. Because of the protective effect of the chitosan-MAc matrix, the orderly layered structure of monetite-chitosan composite is inherited from the layered precursor during the topotactic phase transformation from monetite to HAp.

\section{Mechanical Properties of Organized CaP-Based Composites}

Because the poor mechanical properties of conventional CaP materials limit their application to non- or moderate load-bearing applications, improving their strength is of great interest.

From a clinical point of view, an ideal $\mathrm{CaP}$ bone substitute material should have mechanical properties similar or superior to those of the bone tissue being replaced. To evaluate the mechanical properties of the synthetic CaP-based composites, we prepared bulk tablets via a simple hot-pressing process using layered monetite-chitosan-MAc and organized HApchitosan-MAc composites as the building blocks (Figure S7) and assessed the elastic modulus and hardness of these tablets by nanoindentation. As shown in Table 1, the elastic modulus and hardness of the tablets prepared from layered monetite-chitosan-MAc composite were measured to be $8.78 \pm 0.59$ and $0.31 \pm 0.16 \mathrm{GPa}$, respectively, which are greater than those of conventional bone substitute materials reported in the literatures. ${ }^{63,64}$ For example, the elastic modulus of the monetite-chitosan-MAc tablet was nearly 16 times higher compared to that of conventional $\mathrm{CaP}$ cement $(0.55 \pm 0.09 \mathrm{GPa}) .{ }^{64} \mathrm{By}$ achieving a multilevel ordered structure, the elastic modulus and hardness of the tablets obtained from organized HAp-chitosan-MAc composite were significantly greater, $12.82 \pm 3.74 \mathrm{GPa}$ ( $p<$ $0.001)$ and $0.40 \pm 0.17 \mathrm{GPa}(p<0.05)$, respectively. Remarkably, the elastic modulus of HAp-chitosan-MAc composite tablets was comparable to that of bone $(12.7 \pm 1.7 \mathrm{GPa}$ for cancellous bone and 12.9 $\pm 2.2 \mathrm{GPa}$ for cortical bone) ${ }^{63}$ and human dentin (11.59-16.33 GPa). ${ }^{17}$ This improved mechanical performance could be explained by the extrinsic crack bridging and crack deflection in these hierarchical CaP composite materials. ${ }^{13}$ Specifically, the chitosan-MAc matrix, acting as viscoelastic glue, generates limited deformation between the crystals, thereby allowing the relief of locally high stresses. In addition, the hierarchical structure could toughen the $\mathrm{CaP}$ materials by deflecting the crack path from the plane of 
maximum tensile stress. The improved mechanical properties of the hierarchical $\mathrm{CaP}$ materials, together with their well-known biocompatibility and osteoconductivity, indicate the great potential for hard tissue engineering applications.

To determine the promise of hierarchical $\mathrm{CaP}$ materials as bone substitute materials, future studies are needed to optimize its structure and layers dimensions, investigate the effects of these materials on cellular functions, and study the tissue responses to them in vitro and in vivo. Another subject of further research includes the safety assessment of the ingredients within the hierarchical CaP-based composites. One of the major concerns is the toxicity of maleic acid, which has been shown to be a dermal and/or ocular irritant as a free acid. ${ }^{65} \mathrm{~A}$ possible strategy to lower the concentration of free maleic acid is to neutralize it into various maleate salts. ${ }^{65}$ The design of a $\mathrm{pH}$-sensitive layer that can release the acid in a controlled dose is another strategy that could be used to reduce the toxicity during the degradation of hierarchical CaP-based composites. ${ }^{66}$

\section{CONCLUSIONS}

To achieve hierarchical structure in $\mathrm{CaP}$ materials, we devised a novel pathway to generate a layered monetite composite that can further transform into a HAp composite with a multilevel hierarchical structure. A nacre-inspired matrix composed of chitosan and maleic acid was designed to mediate the construction of an orderly layered structure. The chitosan and MAc molecules assembled into an organized complex and further guided the mineralization of monetite crystals, resulting in the formation of organized and parallel arrays of monetite platelets with a brick-and-mortar structure. By hydrolyzing the layered monetite composite in an alkali solution, hierarchical HAp with multiscale ordered structure was formed through a phase transformation under the mediation of a chitosan-MAc matrix. This hierarchical structure imparts the $\mathrm{CaP}$ material with improved mechanical properties and demonstrates its potential applications in hard tissue engineering. We anticipate that the approach demonstrated here will provide inspiration for biomimetic designs of advanced, mechanically robust materials for biomedical applications.

\section{Supplementary Material}

Refer to Web version on PubMed Central for supplementary material.

\section{Acknowledgments}

Research was supported by NIH-NIDCR grants DE-013414 and DE-020099 to J.M.O. The authors thank the Center for Electron Microscopy and Microanalysis (CEMMA) at University of Southern California for electron microscopy.

\section{References}

1. Inzana JA, Olvera D, Fuller SM, Kelly JP, Graeve OA, Schwarz EM, Kates SL, Awad HA. 3D printing of composite calcium phosphate and collagen scaffolds for bone regeneration. Biomaterials. 2014; 35(13):4026-4034. [PubMed: 24529628]

2. Surmenev RA, Surmeneva MA, Ivanova AA. Significance of calcium phosphate coatings for the enhancement of new bone osteogenesis-A review. Acta Biomater. 2014; 10(2):557-579. [PubMed: 24211734] 
3. Ginebra M-P, Canal C, Espanol M, Pastorino D, Montufar EB. Calcium phosphate cements as drug delivery materials. Adv Drug Delivery Rev. 2012; 64(12):1090-1110.

4. Akkarachaneeyakorn K, Li M, Harris J, Davis SA, Mann S. Bioactive hybrid organogels based on miniemulsion synthesis of morphologically complex polymer/surfactant/calcium phosphate nanostructures. Chem Mater. 2014; 26(20):5965-5972.

5. Geffers M, Groll J, Gbureck U. Reinforcement strategies for load-bearing calcium phosphate biocements. Materials. 2015; 8(5):2700-2717.

6. Canal C, Ginebra MP. Fibre-reinforced calcium phosphate cements: a review. J Mech Behav Biomed Mater. 2011; 4(8):1658-1671. [PubMed: 22098867]

7. Sugawara A, Asaoka K, Ding S-J. Calcium phosphate-based cements: clinical needs and recent progress. J Mater Chem B. 2013; 1(8):1081-1089.

8. Naleway SE, Porter MM, McKittrick J, Meyers MA. Structural design elements in biological materials: application to bioinspiration. Adv Mater. 2015; 27(37):5455-5476. [PubMed: 26305858]

9. Zhao N, Wang Z, Cai C, Shen H, Liang F, Wang D, Wang C, Zhu T, Guo J, Wang Y, Liu X, Duan C, Wang H, Mao Y, Jia X, Dong H, Zhang X, Xu J. Bioinspired materials: from low to high dimensional structure. Adv Mater. 2014; 26(41):6994-7017. [PubMed: 25212698]

10. Mirkhalaf M, Dastjerdi AK, Barthelat F. Overcoming the brittleness of glass through bioinspiration and micro-architecture. Nat Commun. 2014; 5:3166. [PubMed: 24473226]

11. Bouville F, Maire E, Meille S, Van de Moortèle B, Stevenson AJ, Deville S. Strong, tough and stiff bioinspired ceramics from brittle constituents. Nat Mater. 2014; 13(5):508-514. [PubMed: 24658117]

12. Le Ferrand H, Bouville F, Niebel TP, Studart AR. Magnetically assisted slip casting of bioinspired heterogeneous composites. Nat Mater. 2015; 14(11):1172-1179. [PubMed: 26390326]

13. Wegst UGK, Bai H, Saiz E, Tomsia AP, Ritchie RO. Bioinspired structural materials. Nat Mater. 2014; 14(1):23-36. [PubMed: 25344782]

14. Ruan Q, Moradian-Oldak J. Amelogenin and enamel biomimetics. J Mater Chem B. 2015; 3(16): 3112-3129.

15. Halgaš R, Dusza J, Kaiferová J, Kovácsová L, Markovská N. Nanoindentation testing of human enamel and dentin. Ceramics-Silikáty. 2013; 57(2):92-99.

16. Studart AR. Towards high-performance bioinspired composites. Adv Mater. 2012; 24(37):50245044. [PubMed: 22791358]

17. Bai H, Walsh F, Gludovatz B, Delattre B, Huang C, Chen Y, Tomsia AP, Ritchie RO. Bioinspired hydroxyapatite/poly(methyl methacrylate) composite with a nacre-mimetic architecture by a bidirectional freezing method. Adv Mater. 2016; 28:50. [PubMed: 26554760]

18. Li C, Born A-K, Schweizer T, Zenobi-Wong M, Cerruti M, Mezzenga R. Amyloid-hydroxyapatite bone biomimetic composites. Adv Mater. 2014; 26(20):3207-3212. [PubMed: 24634054]

19. He W-X, Rajasekharan AK, Tehrani-Bagha AR, Andersson M. Mesoscopically ordered bonemimetic nanocomposites. Adv Mater. 2015; 27(13):2260-2264. [PubMed: 25704285]

20. He W, Kjellin P, Currie F, Handa P, Knee CS, Bielecki J, Wallenberg LR, Andersson M. Formation of bone-like nanocrystalline apatite using self-assembled liquid crystals. Chem Mater. 2012; 24(5): 892-902.

21. Matlahov I, Iline-Vul T, Abayev M, Lee EMY, Nadav-Tsubery M, Keinan-Adamsky K, Gray JJ, Goobes G. Interfacial mineral-peptide properties of a mineral binding peptide from osteonectin and bone-like apatite. Chem Mater. 2015; 27(16):5562-5569.

22. Yang Y, Lv XP, Shi W, Li JY, Li DX, Zhou XD, Zhang LL. 8DSS-promoted remineralization of initial enamel caries in vitro. J Dent Res. 2014; 93(5):520-4. [PubMed: 24496294]

23. Bradt J-H, Mertig M, Teresiak A, Pompe W. Biomimetic mineralization of collagen by combined fibril assembly and calcium phosphate formation. Chem Mater. 1999; 11(10):2694-2701.

24. Fan Y, Sun Z, Moradian-Oldak J. Controlled remineralization of enamel in the presence of amelogenin and fluoride. Biomaterials. 2009; 30(4):478-483. [PubMed: 18996587]

25. Ruan Q, Zhang Y, Yang X, Nutt S, Moradian-Oldak J. An amelogenin-chitosan matrix promotes assembly of an enamel-like layer with a dense interface. Acta Biomater. 2013; 9(7):7289-7297. [PubMed: 23571002] 
26. Wu D, Yang J, Li J, Chen L, Tang B, Chen X, Wu W. Hydroxyapatite-anchored dendrimer for in situ remineralization of human tooth enamel. Biomaterials. 2013; 34(21):5036-5047. [PubMed: 23578556]

27. Li J, Yang J, Li J, Chen L, Liang K, Wu W, Chen X, Li J. Bioinspired intrafibrillar mineralization of human dentine by PAMAM dendrimer. Biomaterials. 2013; 34(28):6738-47. [PubMed: 23787113]

28. Chen X, Wang W, Cheng S, Dong B, Li CY. Mimicking bone nanostructure by combining block copolymer self-assembly and 1D crystal nucleation. ACS Nano. 2013; 7(9):8251-8257. [PubMed: 23972012]

29. Hu YY, Liu XP, Ma X, Rawal A, Prozorov T, Akinc M, Mallapragada SK, Schmidt-Rohr K. Biomimetic self-assembling copolymer-hydroxyapatite nanocomposites with the nanocrystal size controlled by citrate. Chem Mater. 2011; 23(9):2481-2490.

30. Li L, Mao C, Wang J, Xu X, Pan H, Deng Y, Gu X, Tang R. Bio-inspired enamel repair via Gludirected assembly of apatite nanoparticles: an approach to biomaterials with optimal characteristics. Adv Mater. 2011; 23(40):4695-4701. [PubMed: 21915920]

31. Busch S. Regeneration of human tooth enamel. Angew Chem, Int Ed. 2004; 43(11):1428-1431.

32. Furuichi K, Oaki Y, Imai H. Preparation of nanotextured and nanofibrous hydroxyapatite through dicalcium phosphate with gelatin. Chem Mater. 2006; 18(1):229-234.

33. Ito H, Oaki Y, Imai H. Selective synthesis of various nanoscale morphologies of hydroxyapatite via an intermediate phase. Cryst Growth Des. 2008; 8(3):1055-1059.

34. Zou Z, Liu X, Chen L, Lin K, Chang J. Dental enamel-like hydroxyapatite transformed directly from monetite. J Mater Chem. 2012; 22(42):22637-22641.

35. Liu X, Lin K, Wu C, Wang Y, Zou Z, Chang J. Multilevel hierarchically ordered artificial biomineral. Small. 2014; 10(1):152-9. [PubMed: 23847156]

36. Addadi L, Joester D, Nudelman F, Weiner S. Mollusk Shell Formation: A source of new concepts for understanding biomineralization processes. Chem - Eur J. 2006; 12(4):980-987. [PubMed: 16315200]

37. Levi-Kalisman Y, Falini G, Addadi L, Weiner S. Structure of the nacreous organic matrix of a bivalve mollusk shell examined in the hydrated state using cryo-TEM. J Struct Biol. 2001; 135(1): 8-17. [PubMed: 11562161]

38. Suzuki M, Saruwatari K, Kogure T, Yamamoto Y, Nishimura T, Kato T, Nagasawa H. An acidic matrix protein, Pif, is a key macromolecule for nacre formation. Science. 2009; 325(5946):138890. [PubMed: 19679771]

39. Baskar D, Balu R, Kumar TSS. Mineralization of pristine chitosan film through biomimetic process. Int J Biol Macromol. 2011; 49(3):385-389. [PubMed: 21641923]

40. He L-H, Yao L, Xue R, Sun J, Song R. In-situ mineralization of chitosan/calcium phosphate composite and the effect of solvent on the structure. Front Mater Sci. 2011; 5(3):282-292.

41. Li L, Zhao M, Ding S, Zhou C. Rapid biomimetic mineralization of chitosan scaffolds with a precursor sacrificed method in ethanol/water mixed solution. eXPRESS Polym Lett. 2011; 5(6): $545-554$.

42. Jin J, Hassanzadeh P, Perotto G, Sun W, Brenckle MA, Kaplan D, Omenetto FG, Rolandi M. A biomimetic composite from solution self-assembly of chitin nanofibers in a silk fibroin matrix. Adv Mater. 2013; 25(32):4482-4487. [PubMed: 23788326]

43. Arias JL, Fernández MS. Biomimetic processes through the study of mineralized shells. Mater Charact. 2003; 50(2-3):189-195.

44. Sailakshmi G, Mitra T, Chatterjee S, Gnanamani A. Engineering chitosan using $a, \omega$-dicarboxylic acids - an approach to improve the mechanical strength and thermal stability. J Biomater Nanobiotechnol. 2013; 4(2):151-164.

45. Mitra T, Sailakshmi G, Gnanamani A, Mandal AB. Studies on cross-linking of succinic acid with chitosan/collagen. Mater Res. 2013; 16:755-765.

46. Liu W, Sun S, Cao Z, Zhang X, Yao K, Lu WW, Luk KD. An investigation on the physicochemical properties of chitosan/DNA polyelectrolyte complexes. Biomaterials. 2005; 26(15):2705-11. [PubMed: 15585274] 
47. Tan, ZH., Jin, SH., Li, N. Basic Organic Chemistry. Scientific and Technical Documents Publishing House; Beijing: 2004.

48. Domard A. Determination of N-acetyl content in chitosan samples by c.d. measurements. Int J Biol Macromol. 1987; 9(6):333-336.

49. Feng W, Li Y, Ji P. Interaction of water soluble chitosan with multiwalled carbon nanotubes. AIChE J. 2012; 58(1):285-291.

50. Li W, Liu Y, Perez T, Gunton JD, Sorensen CM, Chakrabarti A. Kinetics of nanochain formation in a simplified model of amelogenin biomacromolecules. Biophys J. 2011; 101(10):2502-2506. [PubMed: 22098749]

51. Li W, Chakrabarti A, Gunton JD. Self-assembly of a bipolar model of biomacromolecules. Langmuir. 2013; 29(14):4470-4476. [PubMed: 23484544]

52. Assis OBG, Bernardes-Filho R, Vieira DC, Filho SPC. AFM characterization of chitosan selfassembled films. Int J Polym Mater. 2002; 51(7):633-638.

53. Wang Z, Zeng R, Tu M, Zhao J. Synthesis, characterization of biomimetic phosphorylcholinebound chitosan derivative and in vitro drug release of their nanoparticles. J Appl Polym Sci. 2013; 128(1):153-160.

54. Liu J, Zhang L, Wang $\mathrm{C}, \mathrm{Xu} \mathrm{H}$, Zhao X. Preparation and characterization of lectin-conjugated chitosan fluorescent nanoparticles. Mol BioSyst. 2010; 6(6):954-7. [PubMed: 20379582]

55. Deemak P, Wanichwecharungruang S, Nonthabenjawan R, Jornjangjun C. Controlling the morphology of self-assemble chitosan through derivatization. J Polym Res. 2011; 18(3):419-424.

56. Yang M, Chen G, Zhao Y, Silber G, Wang Y, Xing S, Han Y, Chen H. Mechanistic investigation into the spontaneous linear assembly of gold nanospheres. Phys Chem Chem Phys. 2010; 12(38): 11850-11860. [PubMed: 20661507]

57. Zhang H, Fung K-H, Hartmann J, Chan CT, Wang D. Controlled chainlike agglomeration of charged gold nanoparticles via a deliberate interaction balance. J Phys Chem C. 2008; 112(43): 16830-16839.

58. Li W, Kanyo I, Kuo C-H, Thanneeru S, He J. pH-programmable self-assembly of plasmonic nanoparticles: hydrophobic interaction versus electrostatic repulsion. Nanoscale. 2015; 7(3):956964. [PubMed: 25463509]

59. Max J-J, Chapados C. Infrared spectroscopy of aqueous carboxylic acids: malic acid. J Phys Chem A. 2002; 106(27):6452-6461.

60. Dosen A, Giese RF. Thermal decomposition of brushite, $\mathrm{CaHPO}_{4} 2 \mathrm{H}_{2} \mathrm{O}$ to monetite $\mathrm{CaHPO}_{4}$ and the formation of an amorphous phase. Am Mineral. 2011; 96(2-3):368-373.

61. Xiao J, Zhu Y, Ruan Q, Liu Y, Zeng Y, Xu F, Zhang L. Biomacromolecule and surfactant complex matrix for oriented stack of 2-dimensional carbonated hydroxyapatite nanosheets as alignment in calcified tissues. Cryst Growth Des. 2010; 10(4):1492-1499.

62. Wang M, Gao J, Shi C, Zhu Y, Zeng Y, Wang D. Facile one-pot synthesis of oriented pure hydroxyapatite with hierarchical architecture by topotactic conversion. Cryst Growth Des. 2014; 14(12):6459-6466.

63. Panzavolta S, Bracci B, Focarete ML, Gualandi C, Bigi A. Fiber reinforcement of a biomimetic bone cement. J Mater Sci: Mater Med. 2012; 23(6):1363-1370. [PubMed: 22528068]

64. Ni GX, Choy YS, Lu WW, Ngan AHW, Chiu KY, Li ZY, Tang B, Luk KDK. Nano-mechanics of bone and bioactive bone cement interfaces in a load-bearing model. Biomaterials. 2006; 27(9): 1963-1970. [PubMed: 16226309]

65. Cosmetic Ingredient Review Expert Panel. Final report on the safety assessment of Maleic Acid. Int J Toxicol. 2007; 26(S2):125-130. [PubMed: 17613135]

66. Sen M, Uzun C, Guven O. Controlled release of terbinafine hydrochloride from $\mathrm{pH}$ sensitive poly(acrylamide/maleic acid) hydrogels. Int J Pharm. 2000; 203(1-2):149-157. [PubMed: 10967437] 


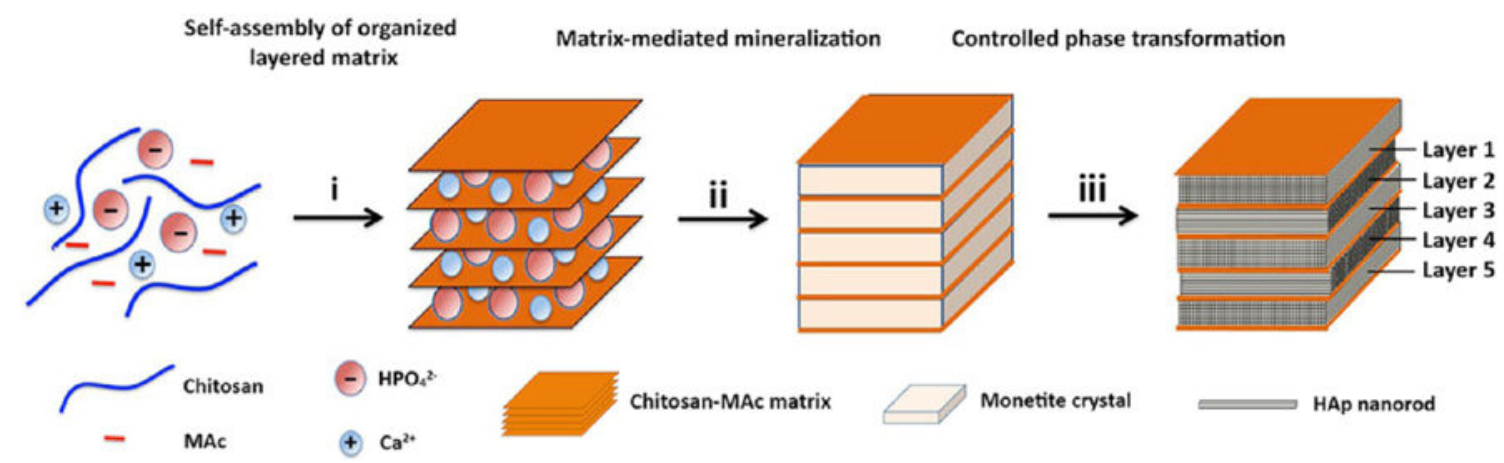

Figure 1.

Schematic representation of the pathway followed to fabricate multilevel organized CaPbased composite. 

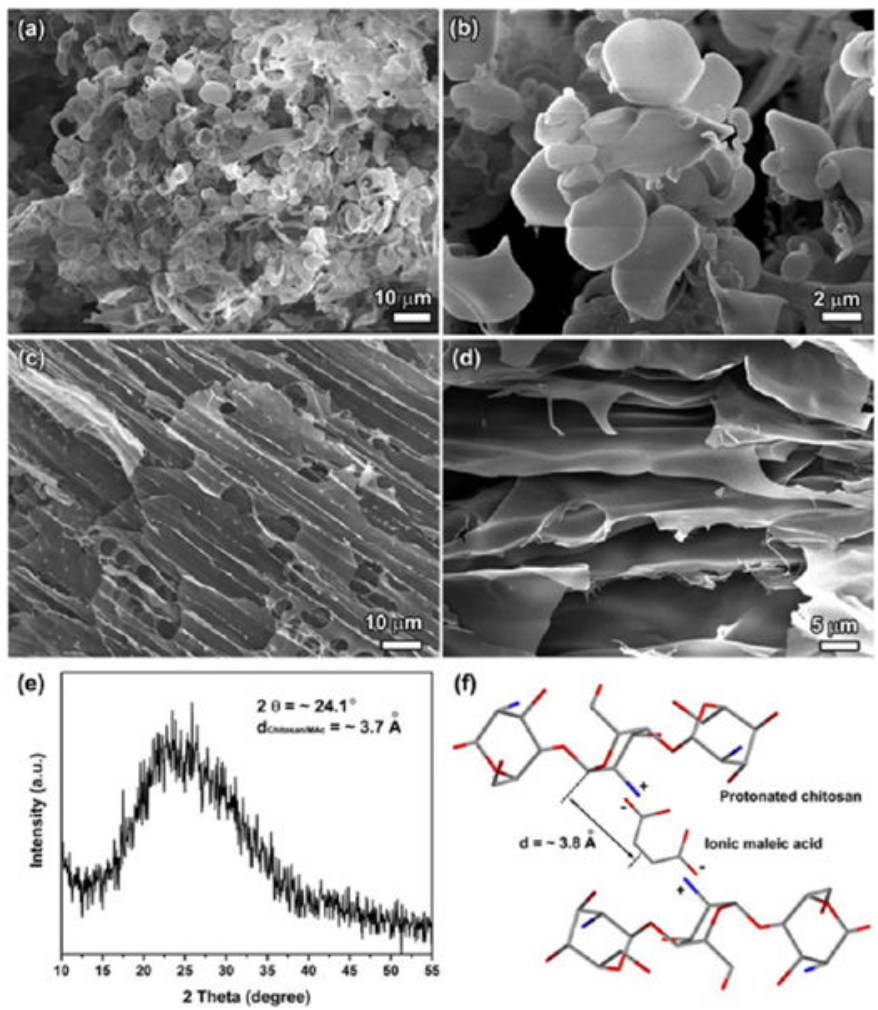

Figure 2.

SEM images of $(a, b)$ pure chitosan matrix and (c, d) organized chitosan-MAc matrix: (a) top view, (b) side view. (e) XRD pattern of chitosan-MAc matrix. (f) Schematic representation of interaction between chitosan and MAc. The molecular model was established by ChemBio Ultra 11.0. The distance between the molecules was estimated using the typical bond lengths and angles. Blue in the chitosan chain and Red in the MAc molecule represent the charged amine and carboxyl groups, respectively. 

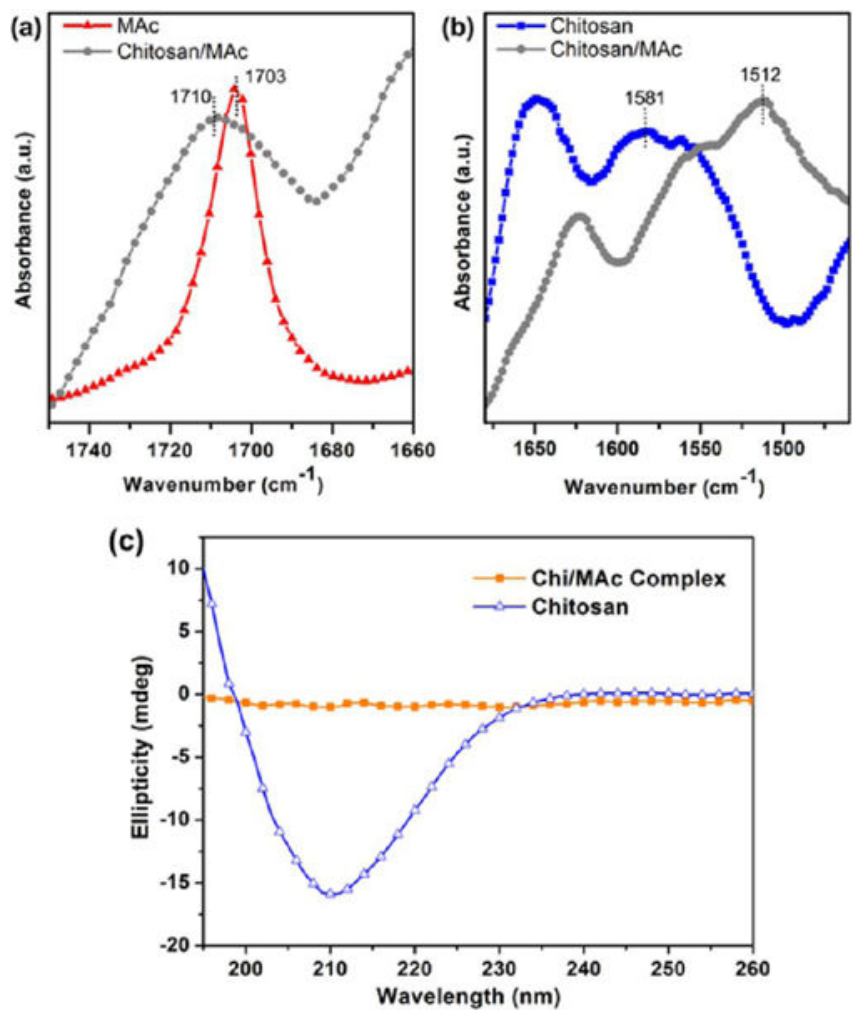

Figure 3.

$(a, b)$ FTIR spectra of chitosan (blue), MAc (red), and chitosan-MAc matrix (gray) in the absence of calcium in (a) the $\mathrm{C}=\mathrm{O}$ stretch and (b) the $\mathrm{N}-\mathrm{H}$ bending regions. (c) $\mathrm{CD}$ spectra of chitosan and chitosan-MAc matrix at $\mathrm{pH} 3.5$. 

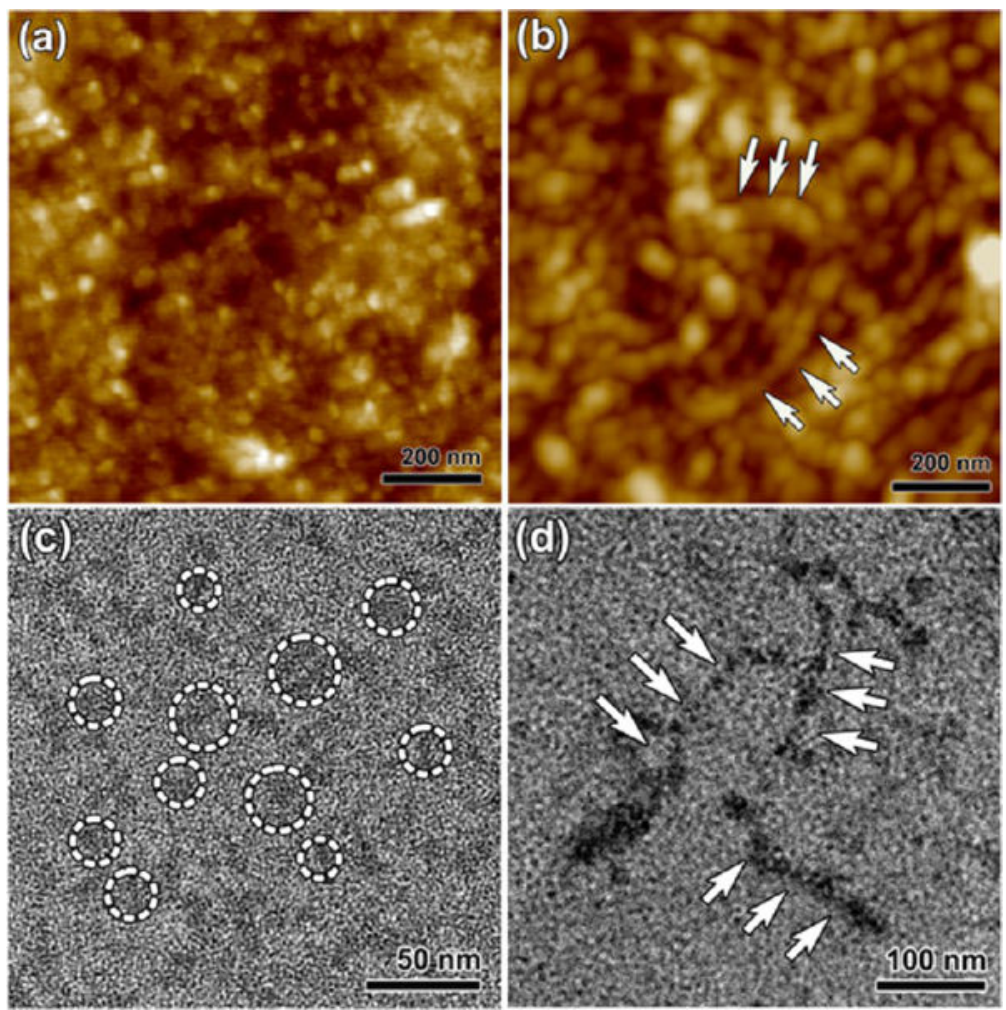

Figure 4.

$(a, b)$ AFM and (c, d) TEM images of $(a, c)$ pure chitosan and (b, d) organized chitosanMAc matrix. 

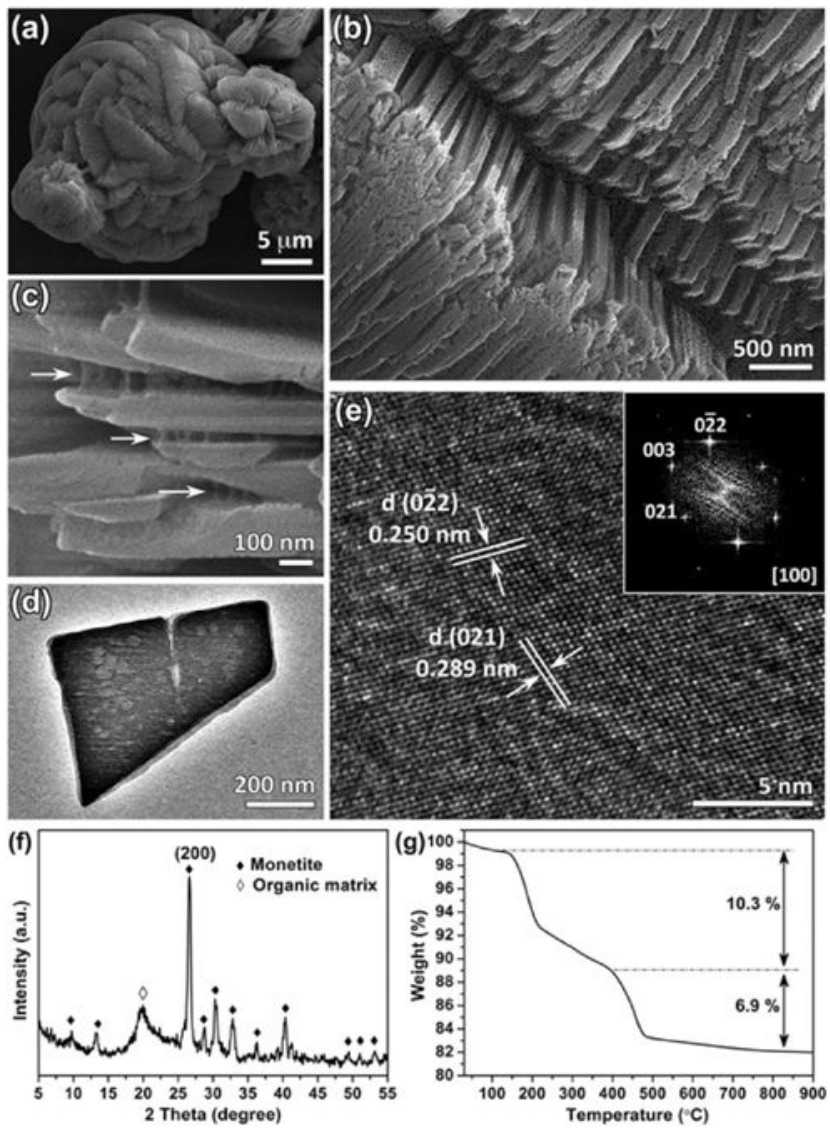

Figure 5.

(a-c) SEM images of the orderly layered monetite-chitosan-MAc composite. (d) TEM and (e) HRTEM images of a monetite nanosheet. Inset: FFT pattern corresponding to e. (f) XRD pattern and (g) TG curve of the layered monetite-chitosan-MAc composite. 
(a) 4

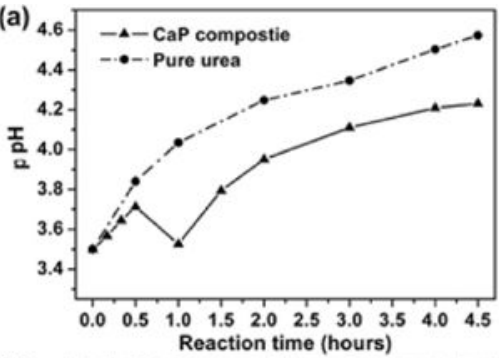

(c)

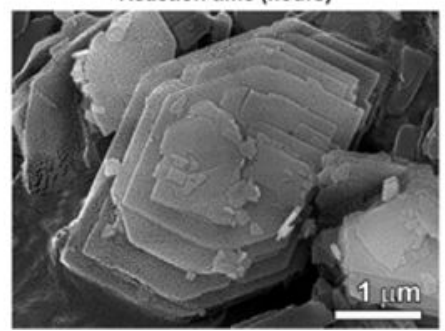

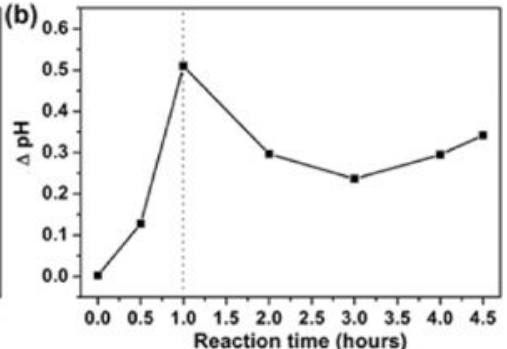

(d)

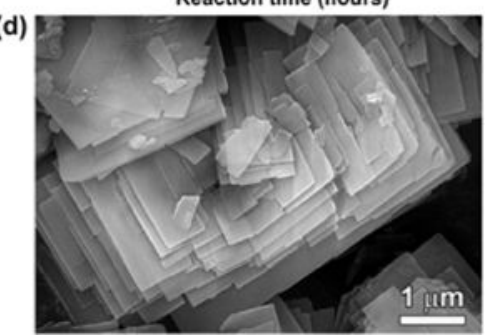

Figure 6.

(a) $\mathrm{pH}$ values of reaction solution without (dotted line) and with (solid line) $\mathrm{Ca}^{2+}$ at different reaction times. (b) $\mathrm{pH}$ difference $(\Delta \mathrm{pH})$ between the solutions with and without $\mathrm{Ca}^{2+}$ at different time points. (c, d) SEM images of the products collected at (c) 1 and (d) $2 \mathrm{~h}$. 

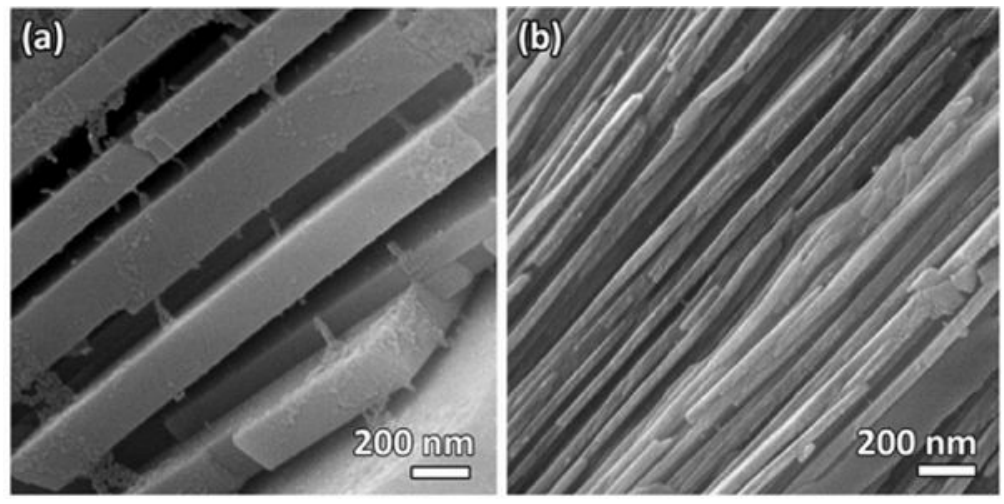

Figure 7.

SEM images of the layered monetite-chitosan-MAc composites formed in chitosan-MAc matrix with different concentrations: (a) $0.5 \%(\mathrm{~m} / \mathrm{v})$ chitosan and $0.2 \%(\mathrm{~m} / \mathrm{v})$ maleic acid; and (b) $3 \%(\mathrm{~m} / \mathrm{v})$ chitosan and $1.2 \%(\mathrm{~m} / \mathrm{v})$ maleic acid. 


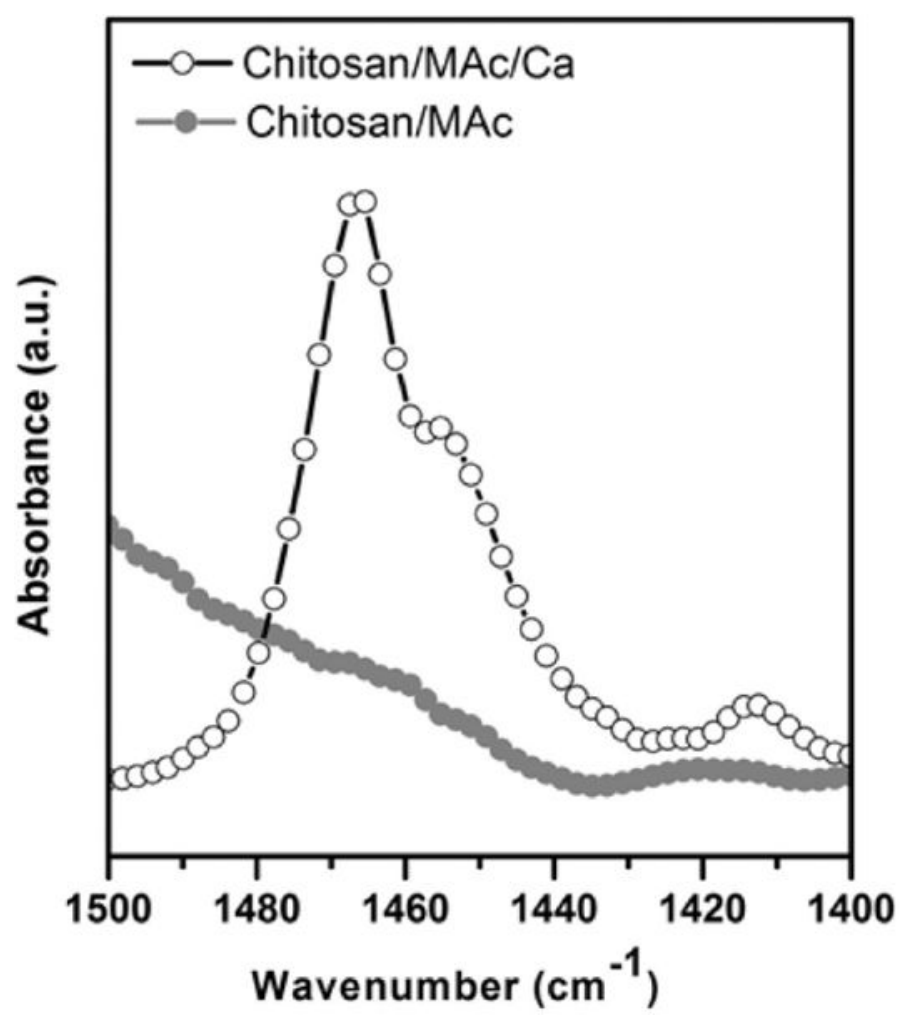

Figure 8.

FTIR spectrum of the chitosan-MAc- $\mathrm{Ca}^{2+}$ complex. 

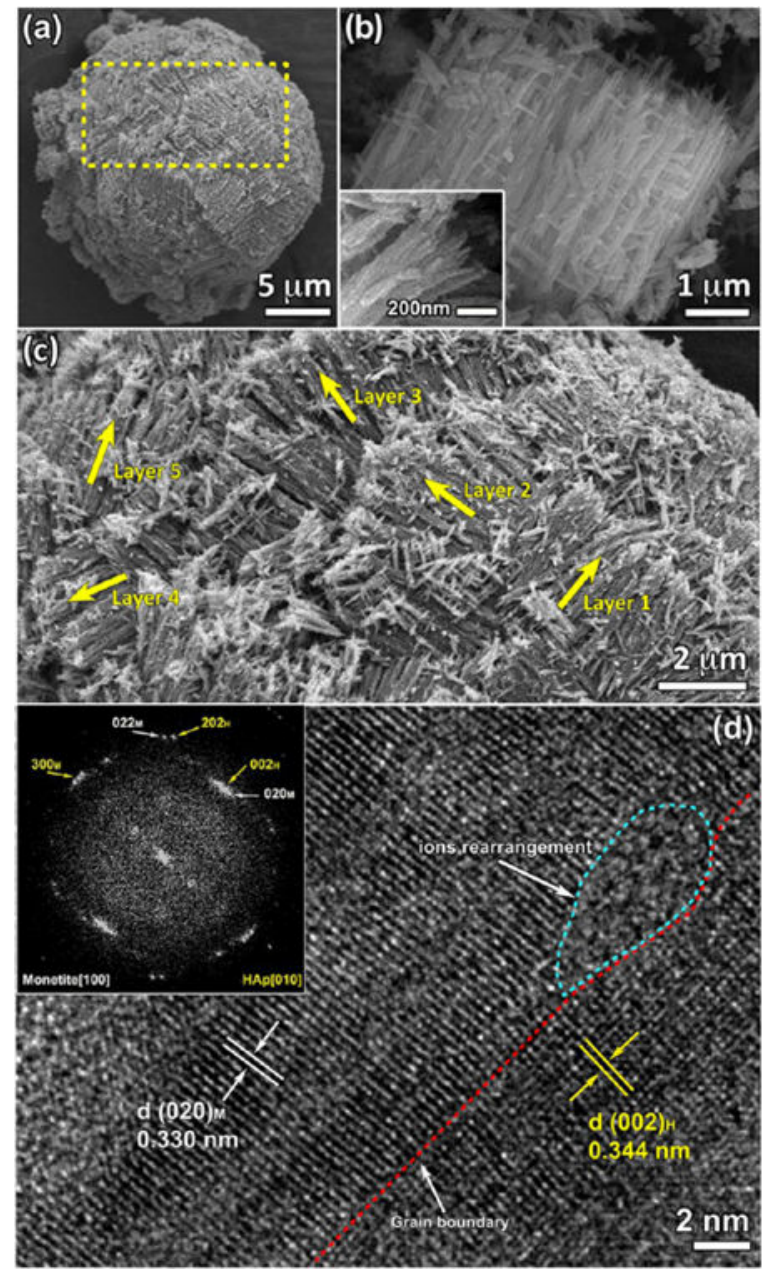

Figure 9.

Organized HAp-chitosan-MAc composite formed from phase transformation of layered monetite-chitosan-MAc composite. (a-c) SEM images of HAp-chitosan-MAc composite. Inset image in b shows the SEM image of an organized bundle. Arrows in (c) indicate different layers (stacks of HAp plates) in the HAp-chitosan-MAc composite. (d) HRTEM images of an isolated crystal from the HAp-chitosan-MAc composite. Inset: FFT pattern corresponding to $\mathrm{d}$. 


\section{Table 1}

Comparison of the Hardness and Elastic Modulus of Reported Bone Substitute Materials, Organized CaPBased Composites, And Natural Biological Materials ${ }^{a}$

\begin{tabular}{|c|c|c|c|c|}
\hline CaP-based materials & & $\begin{array}{l}\text { hardness } \\
\text { (GPa) }\end{array}$ & $\begin{array}{l}\text { elastic modulus } \\
\text { (GPa) }\end{array}$ & ref \\
\hline \multirow[t]{3}{*}{ conventional $\mathrm{CaP}$ materials } & conventional $\mathrm{CaP}$ cement & & $0.55 \pm 0.09 b$ & 63 \\
\hline & fiber reinforced $\mathrm{CaP}$ cement & & $1.03 \pm 0.28^{b}$ & 63 \\
\hline & bioactive CaP substitute & $0.24-0.27^{c}$ & $3.6-5.2^{c}$ & 64 \\
\hline \multirow[t]{3}{*}{ biological CaP materials } & human dentine & $0.52-0.91^{c}$ & $11.59-16.33^{c}$ & 15 \\
\hline & Cancellous bone & $0.63 \pm 0.11^{c}$ & $12.7 \pm 1.7^{c}$ & 64 \\
\hline & cortical bone & $0.89 \pm 0.16^{c}$ & $12.9 \pm 2.2^{c}$ & 64 \\
\hline \multirow[t]{2}{*}{$\begin{array}{l}\text { organized CaP-chitosan-MAc composite } \\
\text { materials }\end{array}$} & layered monetite-chitosan-MAc composite tablet & $0.31 \pm 0.16^{c}$ & $8.78 \pm 0.59^{c}$ & \\
\hline & organized HAp-chitosan-Mac composite tablet & $0.40 \pm 0.17^{\mathcal{c}}{ }^{*}$ & $12.82 \pm 3.74^{c}, * * *$ & \\
\hline \multicolumn{5}{|l|}{$a^{*} p<0.05$ and } \\
\hline \multicolumn{5}{|c|}{ **** $p<0.001$ compared to monetite-chitosan tablets. } \\
\hline \multicolumn{5}{|l|}{$b_{\text {Tested using an Instron testing machine. }}$} \\
\hline
\end{tabular}

